\title{
Effects of Virtual-Reality-Augmented Cardiopulmonary Rehabilitation Programs for Patients with Cardiovascular Diseases: A Systemic Review
}

\author{
I-Wen Penn ${ }^{1,2}$, Eric Chuang ${ }^{3}$, Tien-Yow Chuang ${ }^{4}$, Chen-Ya Yang ${ }^{4, t}$
}

\begin{abstract}
Because of advancements in computer technology, virtual reality has become a novel approach to enhancing the efficacy of medical therapeutic intervention. Its extensive application has gained popularity and scholarly interest because of its real-time generation of desirable environmental and perceptual stimuli. Cardiopulmonary rehabilitation has been regarded as an integral intervention in patients who survive cardiovascular diseases. However, the adherence to and optimal efficacy of cardiopulmonary rehabilitation are often hindered by negative attitudes of participants because of the tedious nature of endurance training. In this systemic review, we comprehensively retrieved and reviewed studies combining virtual reality and cardiopulmonary rehabilitation; we included a total of six clinical studies from the review for further analysis. We explored the underlying reasons for the lack of evidence in the application of virtual reality to cardiopulmonary rehabilitation. We also delineated the problem of developing virtual reality software that is specifically for use in rehabilitation medicine. We conclude that the complexity and cost inhibit the application of virtual reality in the general population. However, augmented virtual reality seems to be a promising candidate for the next generation of cardiopulmonary rehabilitation treatment with strong compliance.
\end{abstract}

\section{Keywords}

Exergame, Cardiovascular disease, Cardiopulmonary rehabilitation, Augmented reality

\section{Introduction}

The breakthroughs in computer technology have led to the development of user-friendly interfaces in various devices. In the 1990s, the increasing accessibility of high-performance computers with swift three-dimensional (3D) graphics generation made nontrivial, effective physical simulations possible at fully interactive speeds in a virtual environment [1,2]. Virtual reality (VR) was later defined as "a realistic and immersive simulation of a $3 \mathrm{D}$ environment, created using interactive software and hardware, and experienced or controlled by movement of the body," and as an "immersive, interactive experience generated by a computer" [3]. The four cardinal elements of a higher level of VR for imitating and recreating real scenarios are outlined as follows: fast calculation by software programs, sensory feedback, immersion, and human-machine interaction [4]. Currently, VR

\footnotetext{
'Department of Physical Medicine and Rehabilitation, Fu Jen Catholic University and Affiliated Hospital, Taiwan

${ }^{2}$ Department of Physical Medicine and Rehabilitation, National Yang-Ming University, Taiwan

${ }^{3}$ Department of Integrative Biology Alumnus, University of California Berkley, Taiwan

${ }^{4}$ Department of Physical Medicine \& Rehabilitation, Taipei Veterans General Hospital, Taiwan

${ }^{\dagger}$ Author for correspondence: Dr. Chen-Ya Yang, Department of Physical Medicine and Rehabilitation, Taipei Veterans General Hospital, No. 201, Section 2, Shih-Pai Road, Beitou District, Taipei City, Taiwan 11217, R.O.C, Tel: +886-2-28757361, Fax: +886-2-28757359, email: mike.ycy@gmail.com
} 
technology is widely used in medical therapies for phobias [5], eating disorders [6], strokes [7], and other neurodegenerative diseases [8], however, two decades ago, when we submitted our first article regarding VR-augmented hand function programs to a journal, it was immediately rejected. The reviewer commented that "We already have rehabilitation programs in the real world. Why do we need a virtual one?" The situation is considerably changed currently, and this is probably because of improvements in computer technology and hardware capacity, as well as the abundance of scientific evidence revealing that VR technology offers more than just a simulated environment. VR, unlike a real-world setting, can construct a creative and suitable environment that interacts with an individual through a more delicate biofeedback fashion than first thought possible.

Applying VR technology to cardiopulmonary rehabilitation $(\mathrm{CR})$ is a relatively novel concept, the aim of which is to transform tedious exercisebased programs into fun programs filled with perceptual stimulation. The concept is to use VR as a facilitator to enhance cardiopulmonary endurance training and promote the beneficial effects of CR. Furthermore, similar concepts have been demonstrated by utilizing various gaming systems in cardiopulmonary rehabilitation, with the aims of raising patients' motivation and engaging them in more regular and challenging training [9-11]. According to our review of the literature, no study has systemically reviewed the benefits of VR in CR. Therefore, we performed a comprehensive review to determine how VR technology interacts with cardiopulmonary exercise training programs, as well as its role in enhancing the efficacy of traditional cardiopulmonary exercise training.

\section{Methods}

\section{- Search strategy}

This study complies with the guidelines set out in Preferred Reporting Items for Systematic Reviews and Meta-Analyses [12]. The aim of the search was to retrieve all published articles related to the use of VR in patients with cardiac diseases who had received Phase I through III CR after acute events. In December 2017, electronic searches were performed in PubMed, Medline, EMBASE, the Cochrane Central Register of Controlled Trials, and the Cochrane Databases of Systemic Review. The time frame ranged from January 2000 to December 2017.

\section{- Study selection}

Studies that were retrieved from the search terms were subjected to further review. The initial search led to the identification of 466 potentially relevant articles. The first reviewer first screened all identified records by titles and abstracts, which excluded 451 records. The remaining records were reviewed in full text, eliminating unqualified studies. Nine more articles were further excluded. Subsequently, the included studies were each independently assessed by the first author and the last author comprehensively to determine the suitability of their inclusion. Ethical approval is not required for a systemic review. Disagreement about the eligibility of a study was resolved by a third reviewer's evaluation (Figure 1). The reason for the high number of excluded studies is that although VR tools are commonly used in cardiopulmonary care to train medical staff, these studies were not in the scope of this review.

\section{- Data extraction and synthesis}

Data from the included studies were extracted using a custom-made, electronic form of Microsoft Excel 2010. Data on study designs, participants, interventions, outcome measurements, and results were presented. Details relating to the interventions included the age of patients, treatment or condition, psychological variables, physiological variables, and intervention settings, as well as the length, frequency, intervention duration, and testing times. A secondary meta-analysis was considered unfeasible due to the heterogeneity of methodological and reporting outcomes across studies. Thus, we adopted a narrative analysis to enable a holistic approach to description and interpretation.

\section{Results}

When we searched the literature regarding the application of VR technology in CR, we observed the included studies to be scant and noted a pronounced heterogeneity between clinical trials. The main results from the studies were grouped according to the treatment or condition. In total, four studies were retrieved (Table 1). One study involved phase I CR immediately after coronary bypass surgery, whereas four studies involved phase II CR. In 2003, Chuang et al. first introduced a $2.5 \mathrm{D}$ VR environment and applied it to cardiopulmonary exercise testing before the initiation of phase II CR. The 
Effects of Virtual-Reality-Augmented Cardiopulmonary Rehabilitation Programs for Patients with Cardiovascular Diseases: A Systemic Review

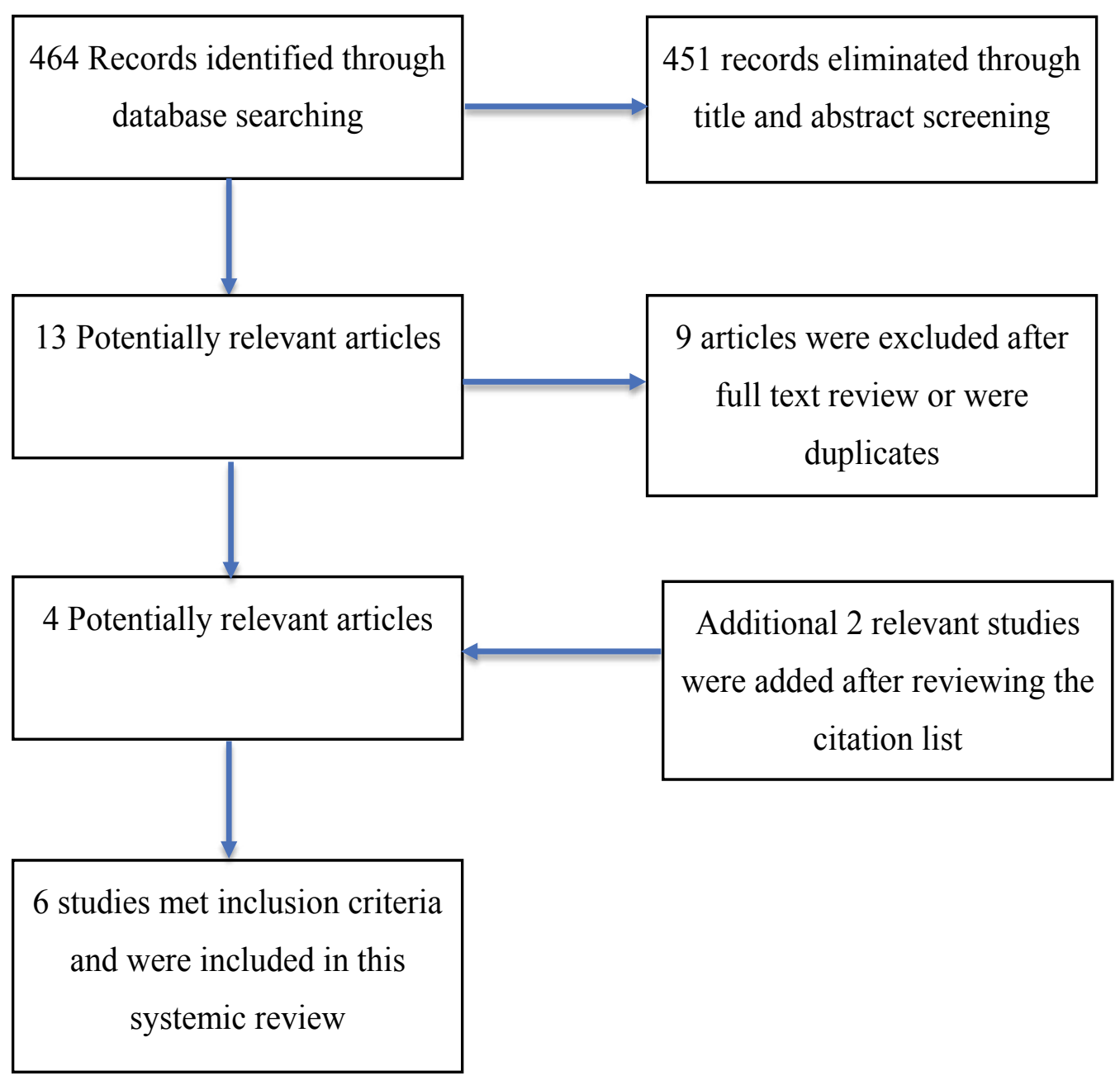

Figure 1: Flow of search and selection through the different stages of the systematic review.

experimental group underwent a maximum graded tolerance test, submaximal endurance VR exercise, and submaximal endurance nonVR exercise. The VR versus non-VR programs showed no difference in submaximal and peak exercise response; however, compared with the control group, the experimental group had a longer duration, longer distance, and greater energy consumption during VR-augmented endurance training [13]. In 2006, Chuang et al. expanded 2.5D VR environments for evaluating the physical capacity of post-coronary artery bypass graft (CABG) participants by using a randomized controlled trial for phase II CR; all participants underwent an in-hospital CR program for 20 sessions [14]. The outcomes revealed that the VR-augmented exercise-based rehabilitation program significantly increased the peak VO2 and metabolic equivalents (METs), compared with the control group. In
2013, Cacau et al. employed full 3D immersion VR technology on a post-CABG population in a randomized controlled trial, comparing VRaugmented phase I CR with the conventional post-CABG CR protocol. The results revealed that the VR-augmented group not only had lower pain levels but also had better functional capacity, as assessed using the functional independence measure (FIM) score, and a better quality of life, as assessed using the Nottingham Health Profile (NHP), compared with the control group [15]. To date, two studies have implemented VR devices in home-based Phase III CR. Both have emphasized the effects of VR intervention on risk factor modification as well as psychosocial and behavioral variables during Phase III CR. Furthermore, in 2017 and 2018, Vieira et al. published two randomized controlled trials comparing a 6-month VRaugmented $\mathrm{CR}$ program with a conventional 


\begin{tabular}{|c|c|c|c|c|c|c|}
\hline Study & Design & $\begin{array}{l}\text { Participant } \\
\text { (number) } \\
\text { Age (years)=mean } \\
\text { (SD) }\end{array}$ & Intervention & $\begin{array}{l}\text { Outcome } \\
\text { measurements }\end{array}$ & Results & $\begin{array}{l}\text { Level of } \\
\text { Evidence }\end{array}$ \\
\hline $\begin{array}{l}\text { Chuang et al. } \\
(2003)\end{array}$ & $\begin{array}{l}\text { Case- } \\
\text { control }\end{array}$ & $\begin{array}{l}\text { Healthy subjects } \\
n=12 \text { Age (years)= } \\
74.5 \text { (4.7) }\end{array}$ & $\begin{array}{l}\text { A submaximal endurance } \\
\text { graded CPET } \\
\text { Submaximal endurance VR vs. } \\
\text { non-VR exercise }\end{array}$ & $\begin{array}{l}\text { Cardiorespiratory and } \\
\text { hemodynamic } \\
\text { parameters at both } \\
\text { peak and submaximal } \\
\text { exertion }\end{array}$ & $\begin{array}{l}\text { VR: longer duration, } \\
\text { distance and higher energy } \\
\text { expenditure for cycling }\end{array}$ & IV \\
\hline $\begin{array}{l}\text { Chuang et al. } \\
(2005)\end{array}$ & $\mathrm{RCT}$ & $\begin{array}{l}\text { Post-CABG } \\
\text { E: } N=25 \text { Age } \\
\text { (years)=68.7 (12.3) } \\
\text { C: } N=24 \text { Age } \\
\text { (years)=64.4 (7.7) }\end{array}$ & $\begin{array}{l}\text { E: Submaximal endurance } \\
\text { programs, with simulated } \\
\text { training } \\
\text { C: Submaximal endurance } \\
\text { programs without simulated } \\
\text { training } \\
\text { 30minutes/session } \\
\text { 2sessions/week } \times 3 \text { months }\end{array}$ & $\begin{array}{l}\text { Cardiorespiratory and } \\
\text { hemodynamic } \\
\text { parameters were } \\
\text { evaluated at both } \\
\text { peak and submaximal } \\
\text { exertion }\end{array}$ & $\begin{array}{l}\text { VR: achieved higher value in } \\
\text { peak oxygen consumption } \\
\text { (VO2peak), } \\
\text { peak metabolic equivalents } \\
\text { (METS), and amount of VO2 at } \\
\text { anaerobic threshold than the } \\
\text { non-VR group }\end{array}$ & $I_{b}$ \\
\hline $\begin{array}{l}\text { Chuang et al. } \\
(2006)\end{array}$ & $\mathrm{RCT}$ & $\begin{array}{l}\text { Post-CABG } \\
\text { E: } N=10 \text { Age } \\
\text { (years)=65.7 (14.8) } \\
C: N=10 \text { Age } \\
\text { (years)=63.7 (10.0) }\end{array}$ & $\begin{array}{l}\text { E: Submaximal endurance } \\
\text { programs, with simulated } \\
\text { training } \\
\text { C: Submaximal endurance } \\
\text { programs without simulated } \\
\text { training } \\
30 \text { minutes/session } \\
2 \text { sessions/week } \times 3 \text { months }\end{array}$ & $\begin{array}{l}\text { Maximum load during } \\
\text { the work sessions, target } \\
\text { oxygen consumption, } \\
\text { target heart rate (beats } \\
\text { per minute), and } \\
\text { number of training } \\
\text { sessions required to } \\
\text { reach rehabilitation } \\
\text { goals. }\end{array}$ & $\begin{array}{l}\text { VR group has a higher rate } \\
\text { of achieving heart rate } \\
\text { and metabolic target goal } \\
\text { compared with non-VR group }\end{array}$ & $I_{b}$ \\
\hline $\begin{array}{l}\text { de Assis Pereira } \\
\text { Cacau et al. } \\
\text { (2013) }\end{array}$ & $\mathrm{RCT}$ & $\begin{array}{l}\text { Post-cardiac } \\
\text { surgery (CABG } \\
\text { and/or valve } \\
\text { replacement) } \\
\text { E: } \mathrm{N}=30 \mathrm{Age} \\
\text { (years) }=49.2(2.6) \\
\mathrm{C}: \mathrm{N}=30 \mathrm{Age} \\
\text { (years) }=52.0(2.4)\end{array}$ & $\begin{array}{l}\text { VR-augmented vs. } \\
\text { Conventional post-op } \\
\text { physical therapy twice a day }\end{array}$ & $\begin{array}{l}\text { FIM, } 6 \mathrm{MWT}, \mathrm{NHP} \text { on } \\
\text { pre-OP, } 1^{\text {st }}, 3^{\text {rd }} \text { post- } \\
\text { operative day and } \\
\text { discharge day }\end{array}$ & $\begin{array}{l}\text { Decreased pain, better } \\
\text { functional capacity, better } \\
\text { 6-minute-walking-distance } \\
\text { and shorter hospital stay in } \\
\text { the VR-augmented group }\end{array}$ & $I_{b}$ \\
\hline $\begin{array}{l}\text { Vieira et al. } \\
(2017)\end{array}$ & $\mathrm{RCT}$ & $\begin{array}{l}\text { Patients } \\
\text { completing } \\
\text { Phase II cardiac } \\
\text { rehabilitation } \mathrm{E}_{1}: \mathrm{N} \\
=11 \text { Age (years) }= \\
55.0(9.0) \\
\mathrm{E}_{2}: \mathrm{N}=11 \mathrm{Age} \\
(\text { years) }=59.0(11.3) \\
\mathrm{C}: \mathrm{N}=11 \mathrm{Age} \\
\text { (years) }=59.0(5.8)\end{array}$ & $\begin{array}{l}\text { VR-augmented vs. } \\
\text { Conventional Phase III home- } \\
\text { based cardiac rehabilitation }\end{array}$ & $\begin{array}{l}\text { Body composition } \\
\text { was assessed with a } \\
\text { bioimpedance scale } \\
\text { and a tape measure; } \\
\text { eating patterns with } \\
\text { the semiquantitative } \\
\text { food frequency } \\
\text { questionnaire; and } 3 \\
\text { months later, the lipid } \\
\text { profile with laboratory } \\
\text { tests. }\end{array}$ & $\begin{array}{l}\text { The VR group exhibited } \\
\text { improvements in the waist-to- } \\
\text { hip ratio after } 6 \text { months }\end{array}$ & $I_{b}$ \\
\hline $\begin{array}{l}\text { Vieira et al. } \\
(2018)\end{array}$ & $\mathrm{RCT}$ & $\begin{array}{l}\text { Patients } \\
\text { completing } \\
\text { Phase II cardiac } \\
\text { rehabilitation } \mathrm{E}_{1}: \mathrm{N} \\
=11 \text { Age (years) }= \\
55.0(9.0) \\
\mathrm{E}_{2}: \mathrm{N}=11 \text { Age } \\
(\text { years) }=59.0(11.3) \\
\mathrm{C}: \mathrm{N}=11 \mathrm{Age} \\
\text { (years) }=59.0(5.8)\end{array}$ & $\begin{array}{l}\text { VR-augmented vs. } \\
\text { Conventional Phase III home- } \\
\text { based cardiac rehabilitation } \\
\end{array}$ & $\begin{array}{l}\text { Ability to switch } \\
\text { information (Trail } \\
\text { Making Test), working } \\
\text { memory (Verbal Digit } \\
\text { Span test), selective } \\
\text { attention and conflict } \\
\text { resolution ability } \\
\text { (Stroop test), quality } \\
\text { of life (MacNew } \\
\text { questionnaire), and } \\
\text { depression, anxiety, } \\
\text { and stress (Depression, } \\
\text { Anxiety, and Stress } \\
\text { Scale). }\end{array}$ & $\begin{array}{l}\text { The VR group exhibited } \\
\text { improved selective attention } \\
\text { and conflict resolution ability }\end{array}$ & $I_{b}$ \\
\hline
\end{tabular}

RCT: Randomized controlled trial CABG: coronary artery bypass graft VR: Virtual reality E: Experimental group C: Control group 
booklet CR program. They concluded that the VR format not only had a positive influence on body composition but also improved selective attention and conflict coping skills among the participants during Phase III home-based CR $[16,17]$.

\section{Discussion}

For the successful application of VR to CR, we propose that three main requirements must be met: (1) The virtual environment and its interface should be adapted to the required performance of the subjects [18-24]; (2) the CR programs should provide quantitative and qualitative methods of evaluation [18]; and (3) the virtual environment should be provided with specific functions that are hoped to be regained, particularly attention, memory, physical strength, and daily living activities [19]. The purpose behind the introduction of such VR equipment is to increase user motivation and adherence to CR for several months [19,20]. Immersion in VR environments diverts attention from unpleasant bodily sensations (i.e., muscular pain and increased breathing), thus delaying the onset of boredom and fatigue [21,22]; this may indeed incite higher participation. In addition to the distraction that VR provides, it has some noticeable indirect benefits for postcardiac event patients. Chuang et al. used power spectrum analysis to assess the sympathovagal modulation of healthy subjects in a virtual cycling environment. The results indicated that using head-mounted devices or the projected virtual display during stationary cycling can reduce sympathetic tone and thus increase blood flow to the muscles prolonging the exercise duration and enhancing fatigue resistance [23]. Furthermore, VR technology was reported to affect psychological response [23]. We published a study on cardiopulmonary endurance exercise with and without a simulated VR scenario; the physical responses of participants were assessed using the Borg rating of perceived exertion scale, the activation-deactivation adjective check list (AD-ACL), and the simulator sickness questionnaire. We discovered that VR technology significantly decreased the participants' anxiety and tension, which is counterproductive to the outcomes of CR [24,25]. Moreover, we observed that the VR experience was extraordinary in that although the participants knew that it was not real, they could still immerse themselves in the scenarios presented and behave similarly to how they would in real situations. This distinguishes
VR from ordinary diversion techniques such as music or television [26]. According to the degree of mutual interactions between a subject and virtual devices, virtual CR can be divided into three categories. The first entails the use highend immersive projected displays in a hospital setting, with the objective of providing enhanced VR exercise-based rehabilitation for patients with myocardial infarction or post-CABG phase I and II CR [14,15,27]. The second involves the use of commercialized game-based exercise programs on platforms such as Sony PlayStation Move, Nintendo Wii, and Microsoft Xbox 360 Kinect, which integrate routine and dull exercise protocols into entertaining video games [28]. The third entails the use of remote physiological signal recording and one-on-one or real-time exercise guidance through the Internet or a portable device. After examining the forms of trials in other studies that used various modalities, we observed that the protocols and outcome measurements employed were diverse. Several concerns exist related to the development of virtual CR. First, the software designation must be aimed at the training goal of the user, from basic function to full recovery of premorbid conditions; the wide spectrum of differences should be stratified delicately. Because the degree of recovery varies between patients, clinicians must carefully and gradually tune patients' training programs to ensure suitability and tolerability. Moreover, programmers should cooperate with clinicians to identify the patients' and clinicians' requirements. Furthermore, to ensure that the software design does not require individual customization, these requirements must be based on the characteristics of a certain disease. Second, the depth of immersion as applied in virtual CR must be determined. The degree of immersion (or presence) is a variable that affects the attention of users. Full immersion can be implemented using a head-mounted display (HMD); a helmet and headphones allow the user to be fully immersed in a computergenerated world-oblivious to visual and auditory stimuli from the real world. By contrast, a computer screen provides a nonimmersive VR experience, because such a screen connects the user to a virtual world while still enabling the user to be conscious and communicative with the real world [29]. Cummings et al. conducted a metaanalysis of studies on the effects of immersion and demonstrated that the depth of immersion was more profoundly influenced by increasing levels of user tracking, the use of stereoscopic visuals, and wider fields of visual display than 
do other immersive system features, including the quality of visual and auditory components [30]. However, extreme levels of immersion are not necessarily beneficial for clinical application. Although employing an HMD could increase the sense of reality and interaction with a scenario, we believe that the use of an HMD in patients with stroke, Parkinson's disease, and spinal cord injuries, as well as in elderly patients, may lead to poor compliance. The reason is that such patients cannot readily accommodate the massive sensory inputs provided by an HMD because of limitations in eye tracking and the limited capacity of perception associated with such patients. New HMDs improving the quality of sensory input have been developed, but such devices may induce unnecessary physiological stress for disabled individuals [31]. However, the cost of the aforementioned devices is high and the market is limited for the general population. Therefore, such devices are mostly established in medical centers and are difficult to promote for use in ordinary clinics or homes. Third, exergaming is gaining ground in treating chronic conditions in a home setting. These active video games not only track body motion but also introduce an exciting new method of exercise $[10,32]$. Various companies have invested in designing game consoles with exergaming interfaces and capabilities because of their recent rise in popularity. Exergaming has been demonstrated to increase energy expenditure to moderate or even vigorous levels [33]. Moreover, successful CR relies on patients' long-term and persistent engagement in physical activity or structured exercise programs; thus, exergaming is a promising modality that promotes adherence through interactivity and real-time feedback [11]. If the software designed could enhance and identify the disadvantages of patients and could be integrated into wearable health devices (now widely available on the market, allowing medical staff to measure physiological variables and detect patients' disabilities synchronously), we are certain that it could be a substitute for expensive VR equipment in home-based CR.

\section{Conclusion}

Studies included in this review were heterogeneous in design, reporting outcomes, and approach. Although studies on VR application in CR are scant, virtual $C R$ has been proved to improve the mental and physical conditions of cardiac patients more effectively than conventional CR programs. However, its complexity and cost inhibit its application in the general population. We predict augmented VR to be a promising candidate for the next generation of CR with good compliance. This will be through a pair of innovative glasses, connecting patients to their surroundings with both reality and virtuality, yet without the inconvenience of motion sickness.

\section{Funding and conflicts of interest}

This research did not receive any specific grant from funding agencies in the public, commercial, or not-for-profit sectors. The authors of this study declare that they have no conflicts of interest.

\section{References}

1. Lewis PH. Sound bytes: he added 'virtual'to'reality'. The New York Times 7 (1994).

2. Chirico A, Lucidi F, De Laurentiis M, et al. Virtual Reality in Health System: Beyond Entertainment. A Mini-Review on the Efficacy of VR During Cancer Treatment. J. Cell Physiol 231(2), 275-287 (2016).

3. Pimentel K, Teixeira K. Virtual reality through the new looking glass. (1993).

4. Sherman WR, Craig ABX. Understanding virtual reality: Interface, application, and design. Elsevier (2002).

5. Wiederhold BK, Jang DP, Gevirtz RG, et al. The treatment of fear of flying: a controlled study of imaginal and virtual reality graded exposure therapy. IEEE 6(3), 218-223 (2002).

6. Ferrer-Garcia M, Gutierrez-Maldonado J, Pla-Sanjuanelo J et al. A Randomised Controlled Comparison of Second-Level
Treatment Approaches for Treatment-Resistant Adults with Bulimia Nervosa and Binge Eating Disorder: Assessing the Benefits of Virtual Reality Cue Exposure Therapy. Eur. Eat. Disord. Rev (2017).

7. Laver KE, George S, Thomas S, Deutsch JE, Crotty M. Virtual reality for stroke rehabilitation. Cochrane Database Syst. Rev 3(2), Cd008349 (2015).

8. Dockx K, Bekkers EM, Van Den Bergh V et al. Virtual reality for rehabilitation in Parkinson's disease. Cochrane Database Syst. Rev 12 Cd010760 (2016).

9. Volmer J, Burkert M, Krumm H et al. Enhancing Long-Term Motivation of Cardiac Patients by Applying Exergaming in Rehabilitation Training. Stud. Health Technol. Inform 237 183-187 (2017).

10. Vieira A, Gabriel J, Melo C, Machado J. Kinect system in home-based cardiovascular rehabilitation. Proceedings of the Institution of Mechanical Engineers. Part $H$, Journal of engineering in medicine 231(1), 40-47 (2017).

11. Verheijden Klompstra L, Jaarsma T, Stromberg A. Exergaming in older adults: a scoping review and implementation potential for patients with heart failure. Eur. J. Cardiovasc. Nurs 13(5), 388-398 (2014).

12. Moher D, Liberati A, Tetzlaff J, et al. Preferred reporting items for systematic reviews and meta-analyses: the PRISMA statement. J. Clin. Epidemiol 62(10), 10061012 (2009).

13. Chuang TY, Chen $\mathrm{CH}$, Chang $\mathrm{HA}$, et al. Virtual reality serves as a support technology in cardiopulmonary exercise testing. Virt. Reality 12(3), (2006).

14. Chuang TY, Sung WH, Chang HA, Wang RY. Effect of a virtual reality-enhanced exercise protocol after coronary artery bypass grafting. Phys. Ther 86(10), 1369-1377 (2006). 
Effects of Virtual-Reality-Augmented Cardiopulmonary Rehabilitation Programs for Patients with Research Cardiovascular Diseases: A Systemic Review

15. Cacau LDaP, Oliveira GU, Maynard LG et al. The use of the virtual reality as intervention tool in the postoperative of cardiac surgery. Braz. J. Cardiovasc. Surg 28(2), 281-289 (2013).

16. Vieira A, Melo C, Machado J, Gabriel J. Virtual reality exercise on a home-based phase III cardiac rehabilitation program, effect on executive function, quality of life and depression, anxiety and stress: a randomized controlled trial. Disabil. Rehabil. Assist. Techno 13(2), 112-123 (2018).

17. Vieira ÁSDS, Cristina Damas Argel De Melo M Andreia Raquel Santos Noites SP, Machado JP, Joaquim Gabriel MM. The effect of virtual reality on a home-based cardiac rehabilitation program on body composition, lipid profile and eating patterns: A randomized controlled trial. Eur. J. Integr. Med 9 69-78 (2017).

18. Sveistrup H. Motor rehabilitation using virtual reality. J. Neuroeng. Rehabil 1(1), 10 (2004).

19. Lieberman DA, Chamberlin B, Medina $E_{\text {, }}$ Franklin BA, Sanner BM, Vafiadis DK. The power of play: innovations in getting active summit 2011. Circulation 123(21), 2507-2516 (2011).

20. Singer RN, Murphey M, Tennant LK. Handbook resear. sport psychol Macmillan, (1993).

21. Annesi JJ, Mazas J. Effects of virtual reality-en hanced exercise equipment on adherence and exercise-induced feeling states. Percept. Mot. Skills 85(3), 835-844 (1997).

22. Annesi JJ. Effects of music, television, and a combination entertainment system on distraction, exercise adherence, and physical output in adults. Can. J. Behav. Sci 33(3), 193 (2001).

23. Huang S-F, Tsai P-Y, Sung $W-H$, Lin C-Y, Chuang T-Y. The comparisons of heart rate variability and perceived exertion during simulated cycling with various viewing devices. Presence 17(6), 575-583 (2008).

24. Chen $C-H$, Jeng $M-C$, Fung $C-P$, Doong J-L, Chuang T-Y. Psychological benefits of virtual reality for patients in rehabilitation therapy. $J$. Sport. Rehabil 18(2), 258-268 (2009).

25. Mcgrady A, Mcginnis R, Badenhop D, Bentle $M$, Rajput $M$. Effects of depression and anxiety on adherence to cardiac rehabilitation. J. Cardiopulm. Rehabil. Prev 29(6), 358-364 (2009).

26. Sanchez-Vives MV, Slater M. From presence to consciousness through virtual reality. Nat.
Rev. Neurosci 6(4), 332-339 (2005).

27. Chuang TY, Sung WH, Lin CY. Application of a virtual reality-enhanced exercise protocol in patients after coronary bypass. Arch. Phys. Med. Rehabil 86(10), 1929-1932 (2005).

28. Ruivo JA. Exergames and cardiac rehabilitation: a review. J. Cardiopulm. Rehabil. Prev 34(1), 2-20 (2014).

29. Biocca F, Levy MR. Communica. age virt. reality Routledge, (2013).

30. Cummings JJ, Bailenson JN. How immersive is enough? A meta-analysis of the effect of immersive technology on user presence. Media. Psychology 19(2), 272-309 (2016).

31. Cobb SVG, Nichols S, Ramsey A, Wilson JR. Virtual reality-induced symptoms and effects (VRISE). Virt. Reality 8(2), (2006).

32. Neves LE, Ceravolo MP, Silva E et al. Cardiovascular effects of Zumba((R)) performed in a virtual environment using XBOX Kinect. $J$. physic. Ther. science 27(9), 2863-2865 (2015).

33. Bailey BW, Mcinnis K. Energy cost of exergaming: a comparison of the energy cost of 6 forms of exergaming. Arch. Pediatr. Adolesc. Med 165(7), 597-602 (2011). 